DOI: $10.2478 / \mathrm{v} \cdot 10169-011-0012-6$

\title{
DEFORMATION OF GEOSYNTHETIC REINFORCED SOIL STRUCTURES BY DESIGN, IN THE LAB AND IN THE FIELD
}

\author{
G. HEERTEN ${ }^{1}$
}

\begin{abstract}
Green-geo-engineering with geosynthetic reinforced soil structures is of increasing practice around the world. Poland is among the leading countries with the third biggest geogrid market in Europe. The German EBGEO 2010 Guideline for Soil Reinforcement with Geosynthetics as first European Guideline for Geosynthetics linked to the Eurocode 7, and the new design code for Japanese railway structures under seismic loading are introduced. New research results from the Geotechnical Institute of the RWTH Aachen, Germany, dealing with the soil/reinforcement interaction and new approaches for design codes for the reinforcement of base courses in traffic areas based on lab and field tests in the USA are presented.
\end{abstract}

Key words: soil structures, geosynthetics.

\section{INTRODUCTION}

During the last years remarkable progress has been made in the design and research of the geosynthetic/soil compound performance. With the German EBGEO 2010, "Guideline for the Design and Calculation of Soil Structures with Geosynthetic Reinforcement", the first guideline linked to Eurocode 7 is available. A translation into English is in progress, but also a translation into the Polish language is discussed currently. This paper will also update some of the present new international developments of geosynthetic reinforced soil structures and will go into new guidelines (concepts and procedures) for the handling of reinforced earth constructions at the Japanese rail under seismic loading, the description of the geosynthetic/soil interaction resulting from investigations under plane strain conditions at the RWTH Aachen University and the further development to the base course design based on lab and field tests in the USA.

For many years economical and ecological advantages of construction methods with geosynthetics in geotechnics and hydraulic engineering are reported already. Comparing traditional construction methods with those using geosynthetics, the latter result in considerable reduction of construction costs and/or construction time and conside-

${ }^{1}$ CEO of NAUE GmbH \& Co. KG, Gewerbestrasse 2, 32339 Espelkamp, Germany. Hon. Professor RWTH Aachen University, Aachen, Germany 
rably less masses that have to be excavated, transported and installed. In addition, there are environmental advantages, for example due to the possibility of greening up geogrid reinforced slopes (Fig. 1).

Also the application of geogrids for base soil reinforcement in traffic areas instead of milling lime/cement binder into the soil shows environmental advantages by having no groundwater impact and no air pollution due to lime/cement dust (Egloffstein, 2009).

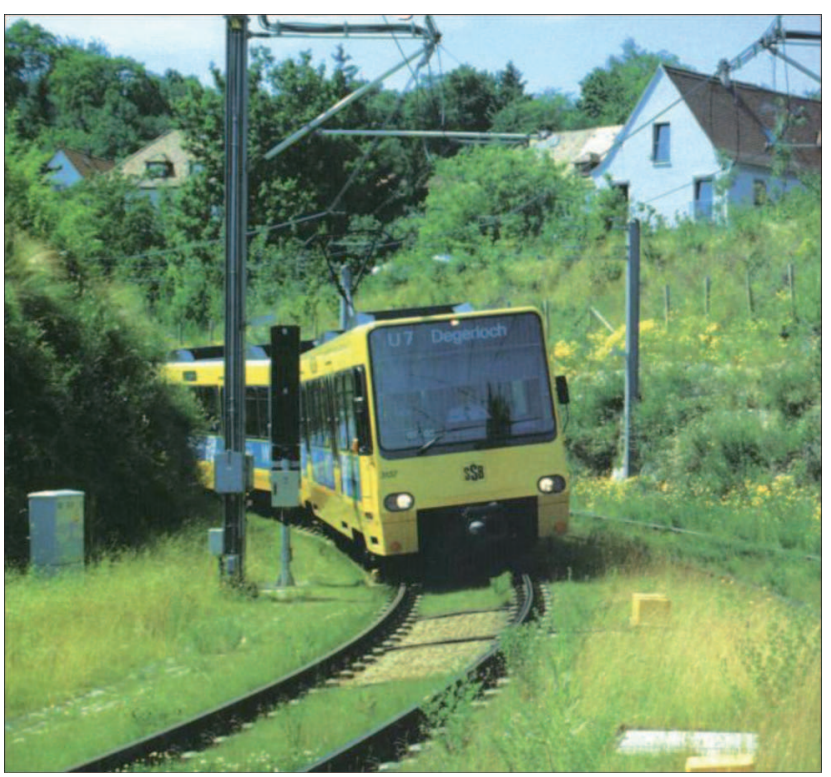

Fig. 1. City railway Stuttgart, Germany. Example of a greened up geogrid reinforced soil structure (1990).

The technical, economical and environmental advantages of geogrid reinforced soil structures will further pass the way that geogrid reinforced soil will become as common as steel reinforced concrete in the future. Poland is among the leading countries having developed to be the third largest geogrid market with estimated 6.4 million $\mathrm{m}^{2}$ in 2009 after the UK and Germany. Actual construction sites like the Motorway A1 near Gorzyczki (Fig. 2). or the North Bridge Warsaw (Fig. 3) are examples for the wide use of soil reinforcement with geogrids.

Already in 1997 Poland pioneered the world with an "erosion proof" dyke design after the Odra flood in 1996. Fig. 4 is showing the cross-section of a reconstructed dyke section which was washed away during the Odra flood. The reconstruction was carried out with a needle-punched geosynthetic clay liner (Bentofix ${ }^{\circledR}$ B4000) as mineral sealing layer and the dyke core was wrapped into staple fibre needlepunched nonwoven geotextiles (SF NP NW GTX) with high robustness (GRK 5 with DIN EN ISO 12236 puncture force $>3.5 \mathrm{kN}$ ), giving future erosion resistance even under overtopping 

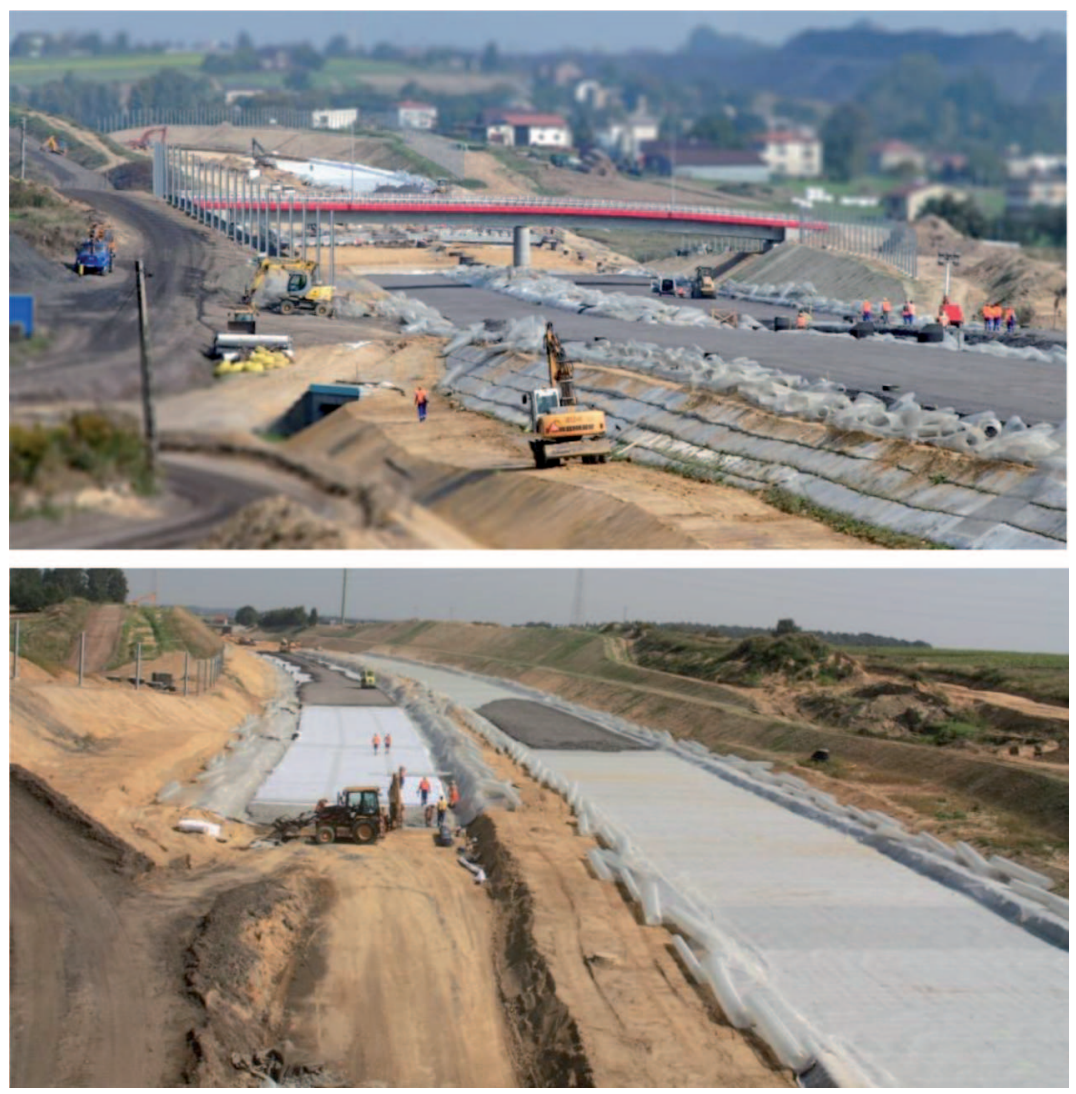

Fig. 2. Highway base reinforcement at Motorway A1 near Gorzyczki, Poland.

conditions. A geotextile filter with a thickness $>4.5 \mathrm{~mm}$ was intsalled for safe and highly effective drainage (Terrafix 609).

\section{RECENT DEVELOPMENTS IN DESIGN AND UNDERSTANDING OF GEOSYNTHETIC REINFORCED EARTH STRUCTURES}

\subsection{New German Guideline EBGEO 2010}

The new German guideline EBGEO 2010 has just been published (Fig. 5), being the first guideline for geosynthetic reinforcement of soil structures linked to Eurocode 7. It is dealing, for example, with the design of steep slopes, embankements, embankements on piles, veneer slope reinforcement. A translation of EBGEO 2010 into English is in progress, a translation into Polish is being discussed between the German Geotechnical Society, the Polish Geotechnical Society and the Publisher. Only for the design of base course reinforcement a design code is still missing also in EBGEO 2010 and 

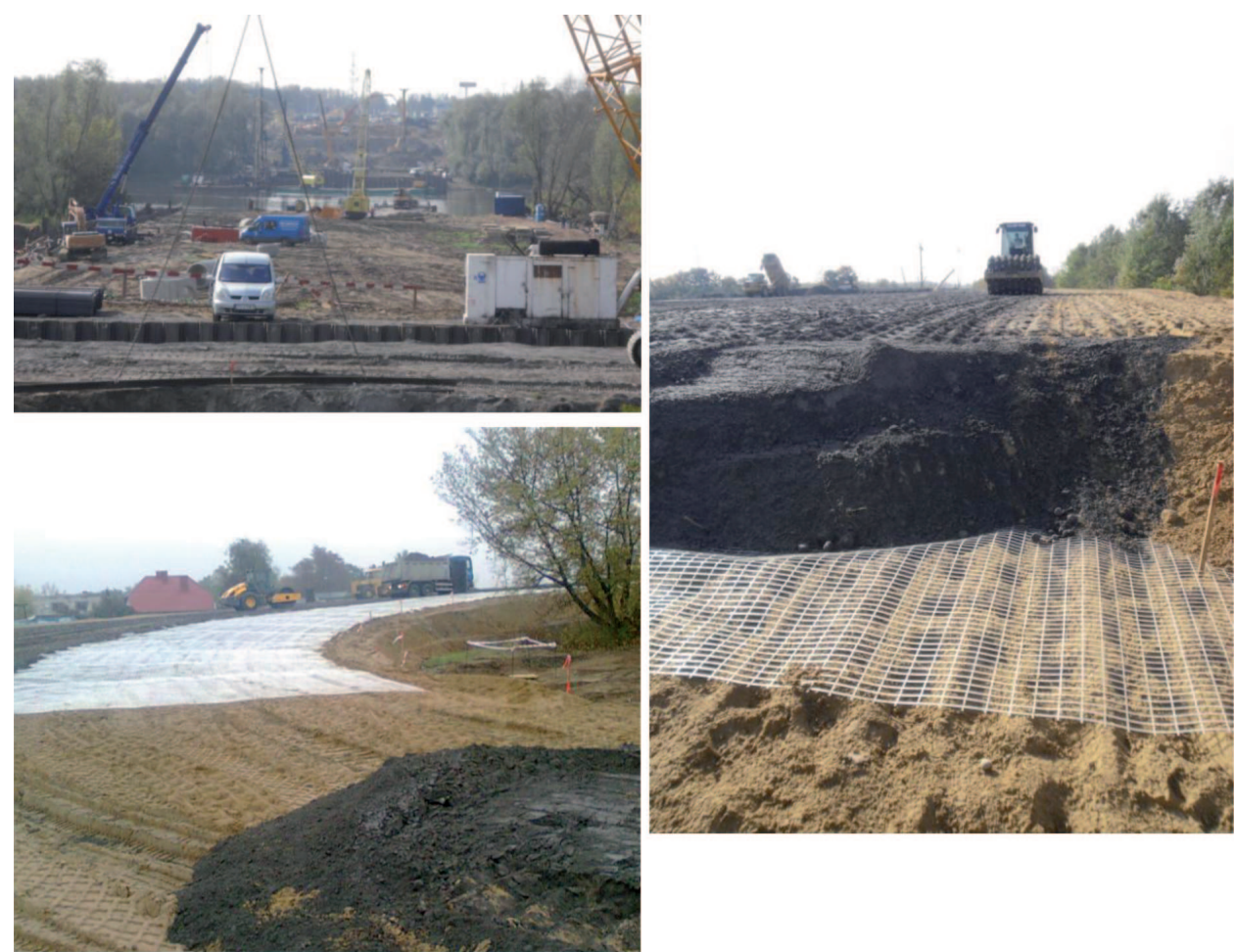

Fig. 3. Embankment reinforcement with geogrids at North Bridge, Warsaw, Poland.

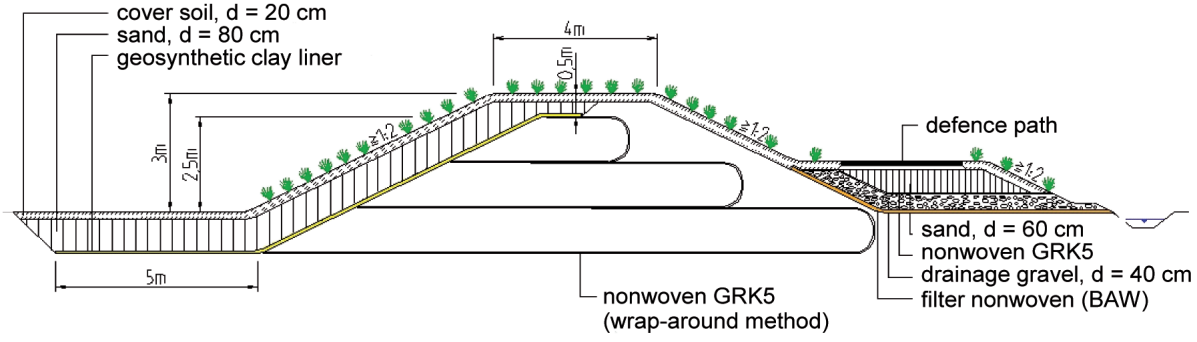

Fig. 4. New safer dyke design (1997, Odra River, Poland. 
reference is given to product-related design codes of the geogrid producers. For the American Association of State Highway and Transportation Officials (AASHTO) a new "Mechanistic-Empirical Design Code" is under development. Details are presented in Chapter 2.4 "Improving the design of geogrid base reinforcement of traffic areas." The actual knowledge and design practice is presented, but there is still a big challenge for future research and development of soil reinforcement with geogrids for a better understanding and description of soil / geogrid interaction.

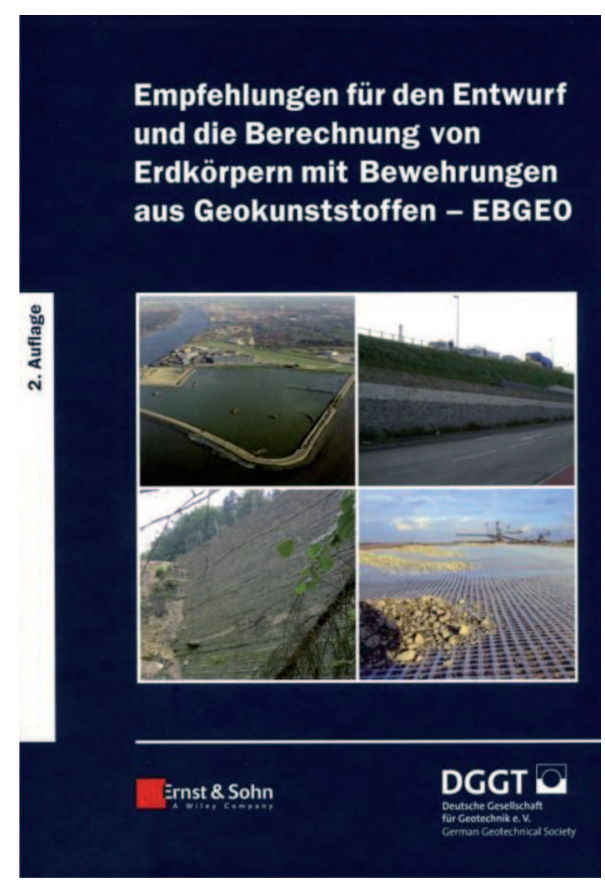

Fig. 5. EBGEO 2010 Guideline for the Design and Calculation of Soil Structures with Geosynthetic Reinforcement (German Geotechnical Society - DGGT e.V.).

\subsection{SEISMiC DESIGN}

The synthetic polymeric materials used for soil reinforcement applications (mainly geogrids) are thermoplastic materials with visco-elastic material properties. The partial safety factor $A_{1}$ for creep is often the most important reduction factor to calculate the design strength $\mathrm{F}_{B i, d}$ of a geosynthetic reinforcing element based on the characteristic tensile strength $\mathrm{F}_{B i, K 0}$ estimated for a given reinforcing product by lab testing. It has to be pointed out again and again that creep of a synthetic reinforcing product is a specific visco-elastic material respond and not a deterioration or damage to the product like e.g. corrosion for metal products. Therefore the special product characteristics 
of polymeric geogrids for soil reinforcement show that after a period of sustained load in a soil structure an additional spontaneous dynamic load can be met by the original short-term tensile strength of the product. In a new seismic design code for Japanese railway structures this background is considered for the first time for design by calculating NO creep reduction to obtain the design tensile strength of geosynthetic reinforcement under additional seismic loading.

The NO-creep-reduction-approach for seismic loading of geosynthetic reinforced structures (GRS) is part of the new concepts and procedures for the recent developed design code for Japanese railway structures reported by Tatsuoka (2009) with the following key elements:

a) very high design seismic loads (i.e., level 2), as those experienced during the 1995 Kobe

earthquake;

b) design against level 2 based on residual displacement;

c) the use of both peak and residual shear strengths with well-compacted backfill;

d) design based on the limit equilibrium stability analysis;

e) control to high backfill compaction and good drainage;

f) strong recommendation of GRS structures as highly earthquake-resistant soil structures;

and

g) no creep reduction to obtain the design tensile strength of geosynthetic reinforcement.

When following this design code, engineers naturally chose GRS structures.

This development is based on the very positive experience with geosynthetic reinforced soil structues under seismic loading in Japan e.g. during the Kobe earthquake. Fig. 6 shows a geosyntehtic reinforced structure (GRS) before and after the Kobe earthquake (Tatsuoka, 2008).

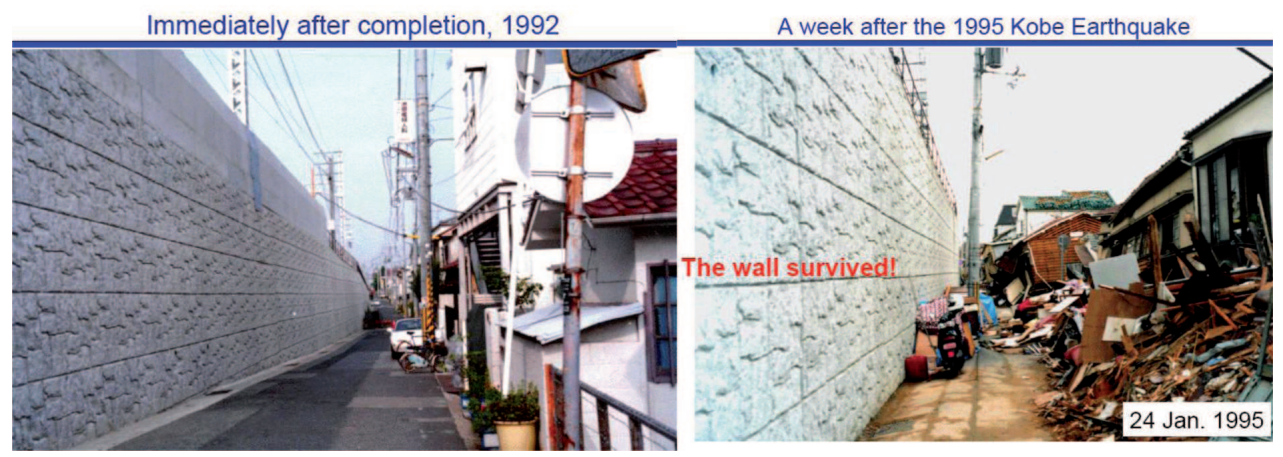

Fig. 6. Geosynthetic reinforced structure (GRS) before and after the Kobe earthquake (Tatsuoka, 2008). 


\subsection{UNDERSTANDING THE SOIL/GEOGRID INTERACTION}

The incorporation of geogrids in soil structures is considerably changing the soil properties and geomechanical behaviour of the "geogrid reinforced soil". As shown in Fig. 7, the properties of the geogrid reinforced soil are governed by the "interlocking effect" with soil particles confined in the geogrid apertures and by arching between the geogrid layers.

On $10^{\text {th }}$ June 2010 roughly 120 visitors came to the Bauhaus University Weimar for a Department of Civil Engineering event entitles "Energy. Experiment. Experience." One of the event's highlights, initiated by Prof. Dr.-Ing. Karl Josef Witt and Dipl.-Ing. Mary Noack, included the first public testing of geogrid-reinforced stone columns - using a 2.2.-ton vehicle. Four columns, each $40 \times 40 \times 30 \mathrm{~cm}$, were constructed in front of the audience. Crushed gravel $8 \mathrm{~mm}-32 \mathrm{~mm}$ was poured into the formwork with Secugrid ${ }^{\circledR} 40 / 40$ Q1 geogrid inserted every $10 \mathrm{~cm}$ to create three layers of reinforcement. Finally, more than $2,200 \mathrm{~kg}$ stood firmly and safely upon Secugrid ${ }^{\circledR}$ 's strength. Test trials in the lab have been executed preliminary. The same columns have withstood a total load of more than 3,000 kg. At this load - still without failure - the test was stopped, giving enough safety for the real test at the event. This load refers to the pressure on the foundation structure of a family home. A video documentation is available at www.naue.com/video-en.

Up to now no satisfactory numerical verification of the "interlocking and arching effect" is possible. Several field and laboratory measurements in geogrid reinforced earth structures show very little elongation of the reinforcing geogrids about $\varepsilon<1 \%$ (Heerten et al., 2009, Vollmert et al., 2010), documentating the confining of soil particles in the soil/geogrid compound material.
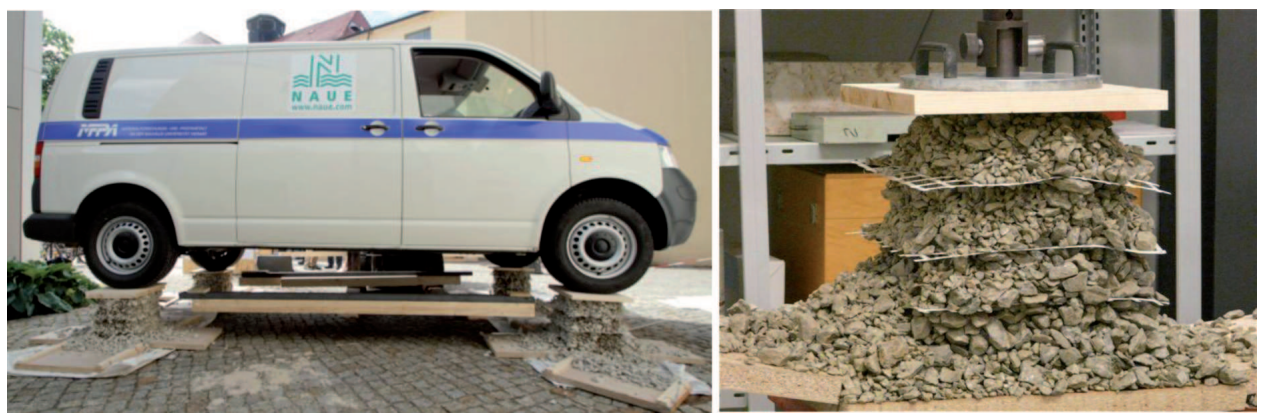

Fig. 7. Geogrid reinforced gravel columns carrying a van (left) and pretesting of gravel columns in the lab (right). 
These elongations are much less than the expected elongations corresponding to the design loads of the geogrids and are not in a creep relevant stress/strain regime of the geogrids, but are in the frames of the serviceability of the compound system governed by the very limited deformation of the soil component itself. Because of the very limited reported deformations of GRS structures hardly any creep deformation of geogrids can be reported from field and large-scale laboratory measurements; thus questioning the actual long-term material properties investigation of geogrids in traditional creep tests. In these tests strength/strain parameters are studied far above the serviceability deformation of soil as deformation limiting part of the soil/geogrid compound material.

Current intensive research - cofinanced by Colbond bv, The Netherlands, and NAUE GmbH \& Co. KG, Germany - on the still existing secrets and challenges of soil/geogrid interaction is carried out at the Geotechnical Institute of the RWTH Aachen University, Germany. After first steps of pull-out tests and large triaxial tests (Ziegler et al., 2008), large-scale plane strain tests are conducted at present. The large triaxial and the plane strain tests are simulating the transfer from forces from the soil into the reinforcing geogrid as it is the case in the field. These test conditions are in contrast to pull-out tests where the load introduced by pulling the geogrid is transferred to the soil. The large-scale test facility at the RWTH Aachen Geotechnical Institute is shown in Fig. 8.

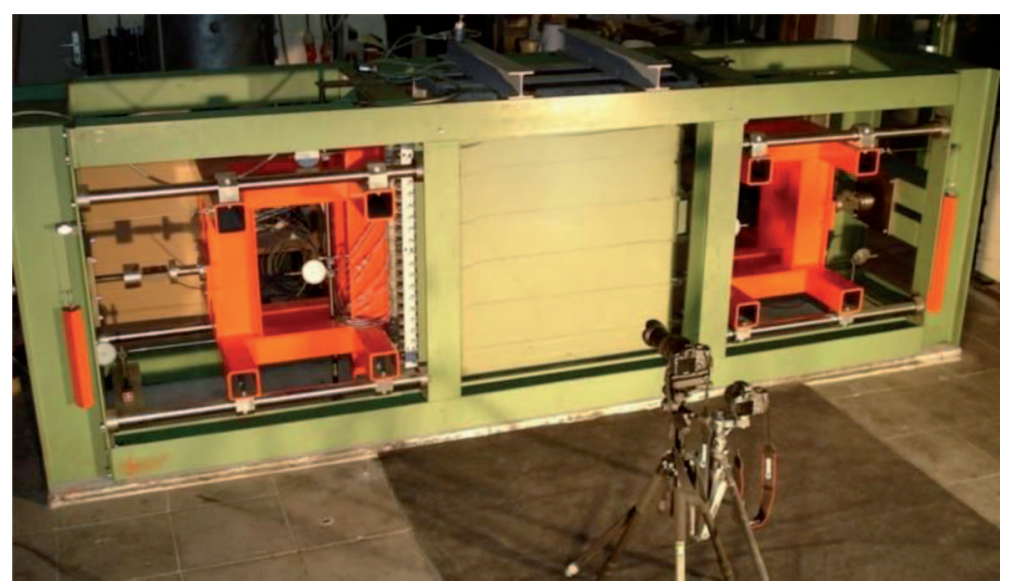

Fig. 8. Lab test facility for plane strain testing of geogrid reinforced soil structures at RWTH Aachen Geotechnical Institute with nearly $0.5 \mathrm{~m}^{3}$ of soil/geogrid structure for plane strain testing

In the test box reinforced soil structures of $1.0 \mathrm{~m} \times 1.0 \mathrm{~m} \times 0.45 \mathrm{~m}$ can be installed and tested by loads up to $50 \mathrm{kN} / \mathrm{m}^{2}$. Based on very stiff steel frames and a glas front of $106 \mathrm{~mm}$ thickness maximum deformations of the soil container are less than $0.1 \mathrm{~mm}$. Any soil particle and geogrid movement can be recorded with remote controlled digital cameras and analysed with the computer-aided PIV method (particle image velocimetry). More details of testing the soil/geogrid compound and of the present results have 
been presented by Ruiken and Ziegler (2010a) and have been published in the paper "Determination of the Soil Confining Effect of Geogrids" by Ruiken and Ziegler for the 14th Danube-European Conference on Geotechnical Engineering, Bratislava, Slovakia, 2-4 June 2010. But it can be mentioned already now that for a geogrid reinforced sand without connection to the moveable front plate a reduction of earth pressure up to $60 \%$ at the front plate and very little soil movement and geogrid elongation have been observed. The soil/geogrid compound is already "activated" during installation of the reinforced soil sample as a "preloading" before the movement of the front plate starts. By moving the front plate the soil confining caused by the geogrid layers is obvious. Little grain movement is limited to a narrow area behind the front plate by arching between the geogrid layers with the development of several shear planes close to the front plate (Fig. 9).

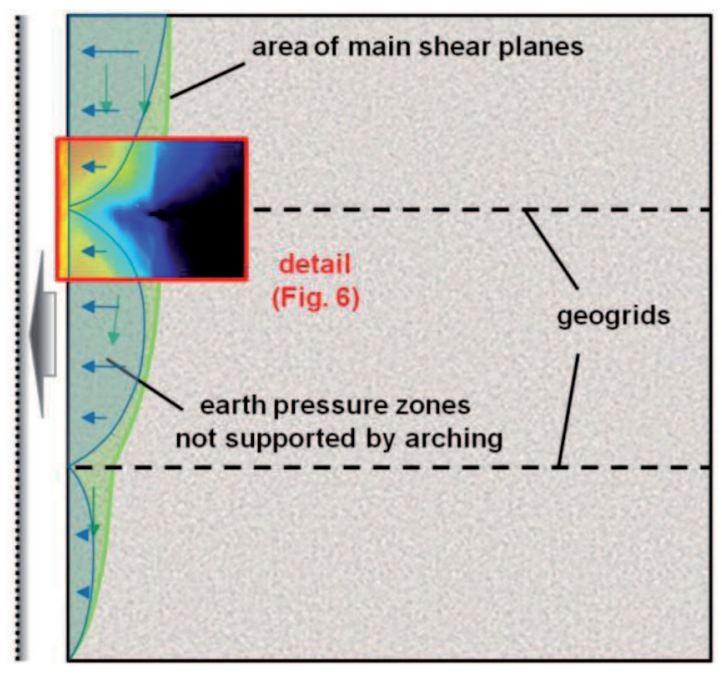

Fig. 9. Main shear planes and arching effects of geogird soil reinforcement, in plane strain testing of $1.0 \mathrm{~m} \times 1.0 \mathrm{~m} \times 0.45 \mathrm{~m}$ reinforced soil specimen.

Shear planes are predominantly crossing vertical to the geogrid layer indicating no tensile activation of the geogrids, but probably causing confining which is shown in Fig. 10 with a strong reduction of horizontal movement of the soil particles close to the geogrid layer.

The maximum deformations of the geogrid are $\varepsilon<<1 \%$ indicating again a very stiff confined geosynthetic reinforced soil area with a completely different behaviour of the geogrid compared to traditional tensile or creep testing in air. The present results are showing again that a lot of questions have to be answered by future research before we fully understand the geogrid/soil interaction and are able to carry out corresponding numerical calculations and designs. Considering the very complex soil/geogrid interaction of soil confining and shear plane development it may be expected that different 

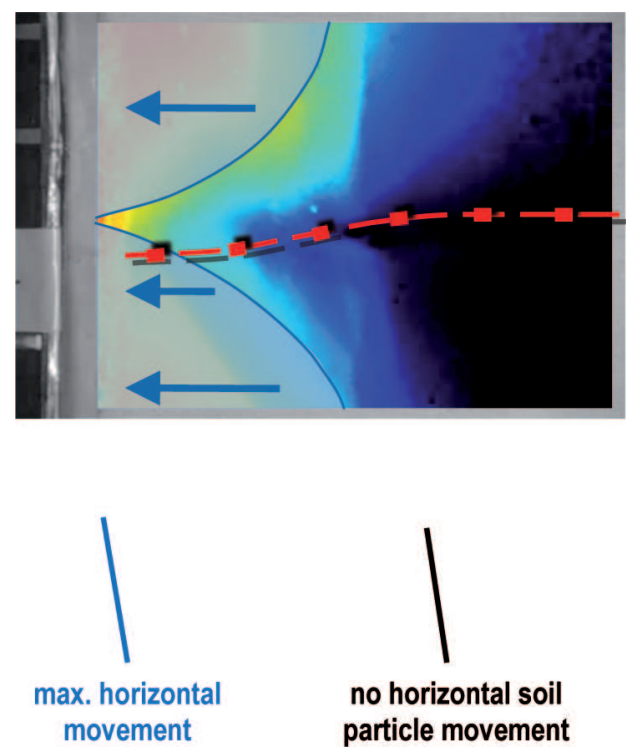

Fig. 10. Horizontal grain movement behind the front plate and corresponding grain confining by the geogrid layer.

soil reinforcement techniques e.g. with steel or synthetic strips, woven fabrics with a close surface and open structured geogrids will show different soil/reinforcement interactions and therefore different soil reinforcement effects, thus asking for different design methods and design parameters.

But it is important to know and to consider that the actual state-of-the-art design approaches for geogrid reinforced soil structures are very safe, provided that good compaction and drainage are additionally considered and carried out. Again: GRS structures are very safe at present, superior under seismic loading, environmentally friendly and of high cost effectiveness. The known ductile failure mode of these structures is an additional important advantage.

With the new EBGEO 2010 linked to Eurocode 7 (EC-7) in Germany, a further step in the right direction of more effective and realistic design methods for reinforced slopes is taken. EBGEO allows for a reduction of the lateral stress as compared to the Rankine's active earth pressure. The well known coefficient for the lateral active earth pressure $\mathrm{k}_{a k}$ is just used as basic parameter (Eq. 2.1), taking the inclination of the wall as well as the soil parameters (e.g. angle of internal friction $\varphi^{\prime}$ ) into consideration. The correction factor $\eta_{G}$ as per Fig. 11 is then applied, knowing well that using the lateral active earth pressure $\mathrm{k}_{a k}$ as basic parameter is just an interim solution up to full understanding and modelling of reinforced earth. In the upper part of the construction respectively on the actual construction level, the earth pressure due to compaction (not shown in Fig. 11) becomes decisive, but is going to be superposed by the earth pressure resulting from the self-weight of the construction as per Fig. 11. 

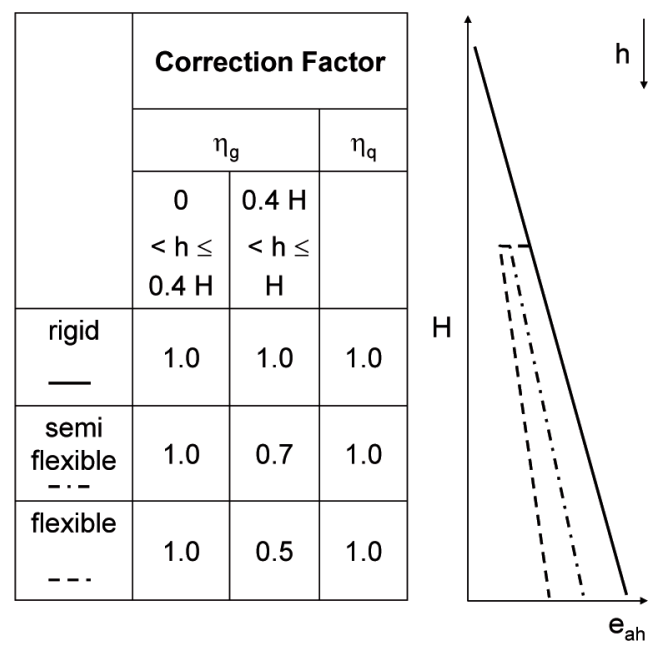

Fig. 11. Correction factors applied to $\mathrm{k}_{a h}$ according to EBGEO, 2010.

$$
E_{\text {Facing }}=\left(\eta_{g} * k_{a g h, k} * \gamma_{k} * H_{i} * \gamma_{G}+\eta_{q} * k_{a q h, k} * q * \gamma_{Q}\right) * l_{v}
$$

with $\mathrm{E}_{\text {Facing }}$ Earth pressure on facing element $[\mathrm{kN} / \mathrm{m}]$

$\eta_{g}, \eta_{q}$ Matching coefficient for self-weight (g) and life load (q) [-]

$\mathrm{k}_{a g h, k}, \mathrm{k}_{a q h, k}$ Coefficient active earth pressure [-]

$\gamma_{k}$ Weight per unit area of the soil $\left[\mathrm{kN} / \mathrm{m}^{3}\right]$

$\mathrm{H}_{i}$ Covering [m]

q Traffic load $\left[\mathrm{kN} / \mathrm{m}^{2}\right]$

$\gamma_{G}, \gamma_{Q}$ Partial safety factor DIN $1054[-]$

$1_{v}$ Vertical space between layers $[\mathrm{m}]$

Special attention has to be paid to the facing system. Current development shows that friction connection can be a proper and economic solution while the serviceability can be increased by using welded geogrids with a comparatively high secant stiffness (Fig. 12).

Executed large-scale tests as well as site measurements indicate again that the actual design is by far on the safe side. This is e.g. shown on two monitored steep slopes which are constructed with the "wrap-around method" and steel mesh facing elements: the noise protection barrier Bammental, Germany, having a height of $18 \mathrm{~m}$ and $70^{\circ}$ inclination, the geogrid reinforced steep slope at Valdecaňas Island, Spain, shows a height of $21 \mathrm{~m}$ and also $70^{\circ}$ inclination. All monitoring details and field data are collected from the geogrids in service. The measurement data are showing the real situation after the geogrids have been loaded by the steep slope structure, have survived all construction activities and have been exposed to all environmental impacts 

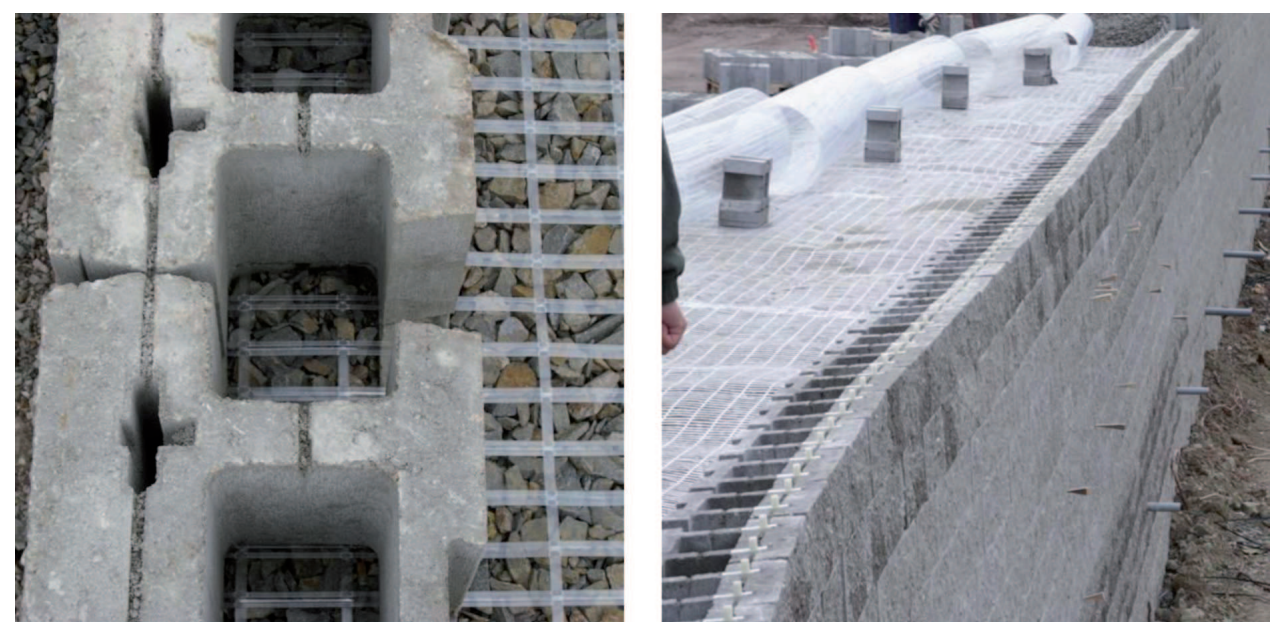

Fig. 12. Block wall with friction connection under construction, Zanovica (SK), 2009, (Vollmert et al., 2010).

over the service time. Therefore, all service and safety relevant impacts are included in the actually documentated condition.

Fig. 13 exhibits the monitoring details and the less than $\varepsilon=0.1 \%$ strain values of the geogrid after 4,500 $\mathrm{h}$ (about half a year) close to the bottom of the steep reinforced slope at Bammental.

Fig. 14 is showing the cross-section of the Valdecaňas steep reinforced slope with the positioning of strain gauges in one geogrid layer close to the bottom of the structure and the strain developments during construction to the final height of 29 soil reinforced layers (5 months construction time) and the situation after additional 4 months. More details are given in Vollmert et al. (2010).

Another example of monitoring the strain development of geogrid reinforcement over time has been presented by Werth (2010). In this case a $40 \mathrm{~m}$ long 1:2 slope of a landfill capping has been instrumented with strain gauges from the bottom to the top of the slope as shown in Fig. 15.

The cover system of the landfill is designed with (from bottom to top)

- a levelling layer

- textured HDPE geomembrane $(\geq 2.5 \mathrm{~mm})$

- geosynthetic drainage layer

- geogrid (400/40 kN/m, MD/CD)

- cover soil with a thickness of $1.6 \mathrm{~m}$

From the design considering all relevant partial safety factors (creep, installation damage, environment), the long-term design strength of the geogrid is estimated to $46 \%$ of the short-term strength of the product $(46 \%$ of $400 \mathrm{kN} / \mathrm{m}=183 \mathrm{kN} / \mathrm{m}$ long-term design strength). The readings of the strain gauges from the bottom (gauge 1) to the 

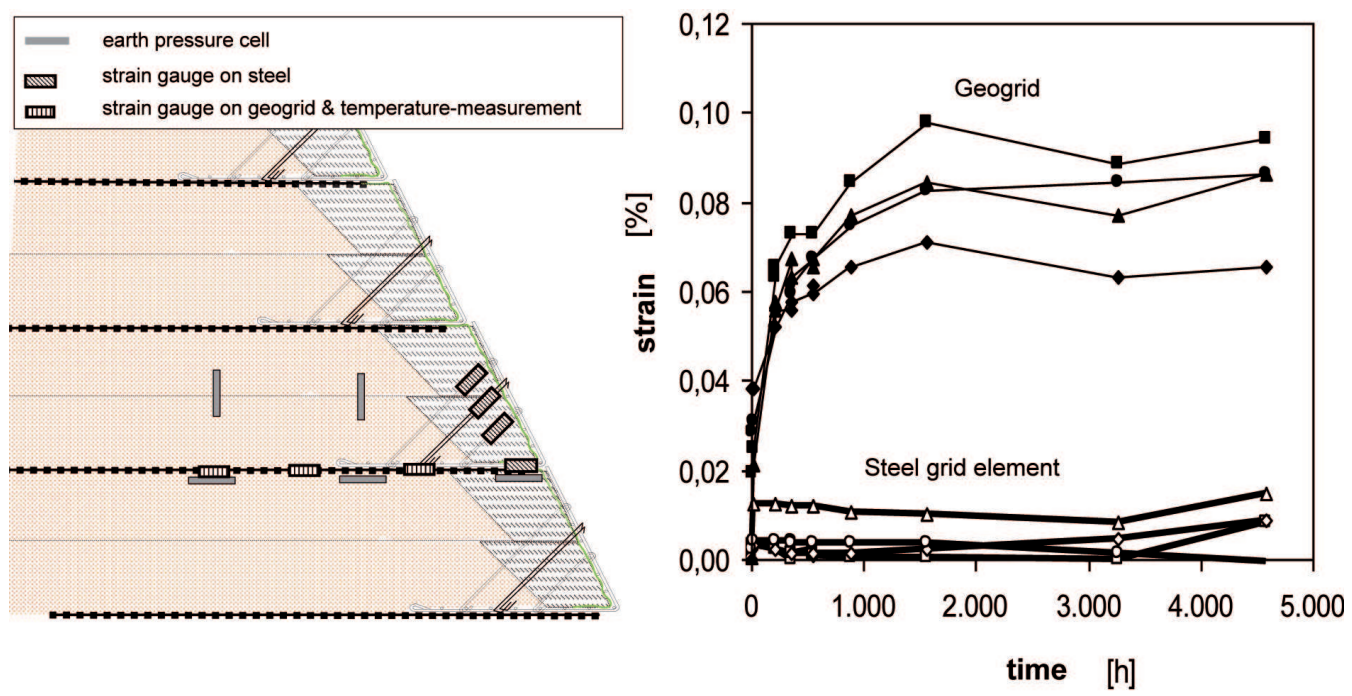

Fig. 13. Detail for measurement application and strains versus time at the steep reinforced slope at Bammental, Germany.
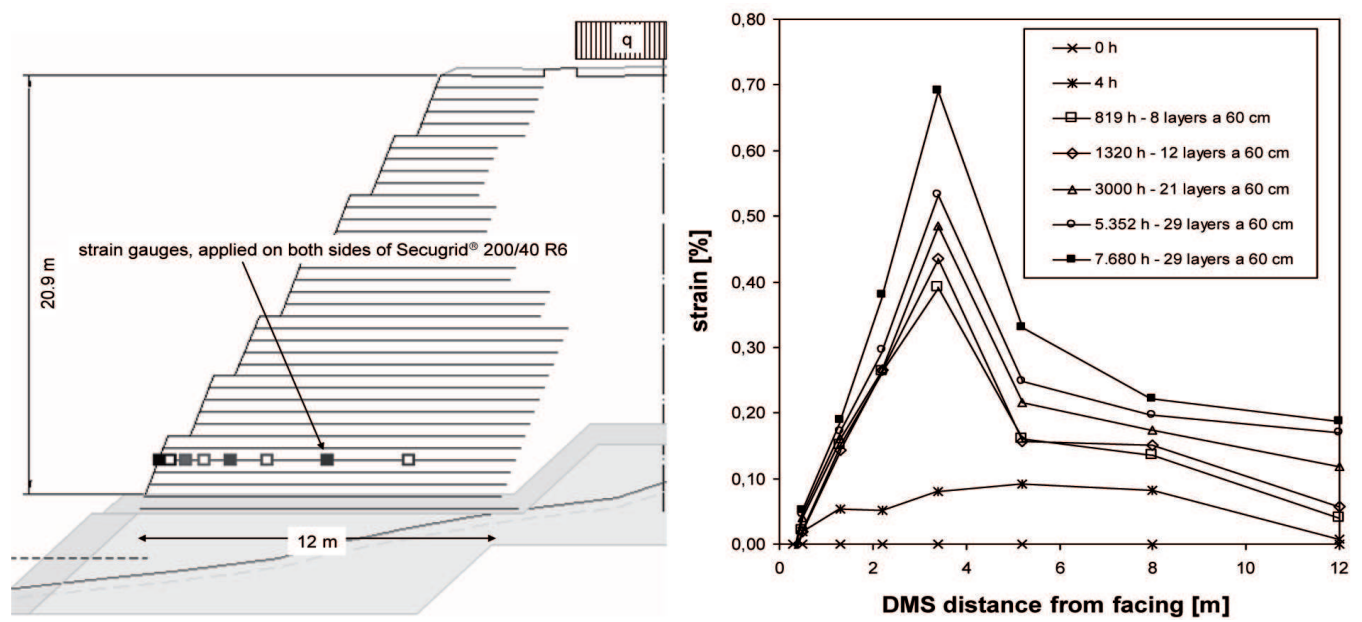

Fig. 14. Cross-section of steep slope Valdecaňas and results of strain measurements. Steep embankment at Sierra de Gredos, Spain. 


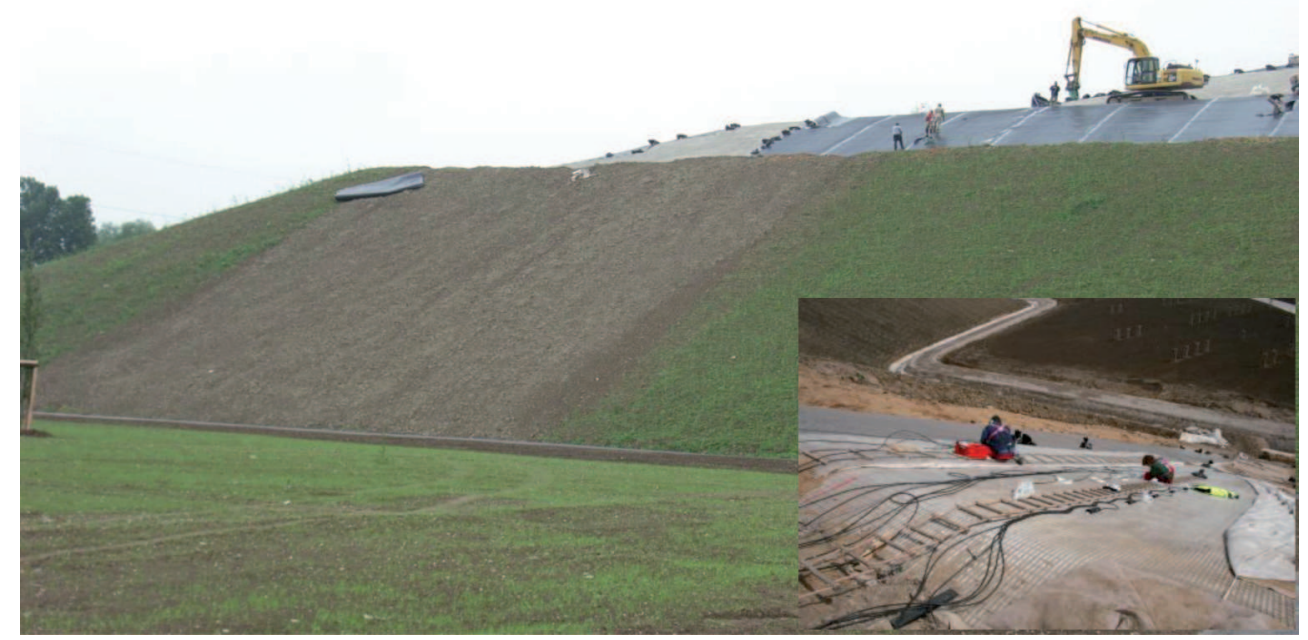

Fig. 15. Creep monitoring of veneer reinforcement at Sudamin landfill, Germany, 2008.

top (gauge 6) after finishing the construction of the slope are shown in Fig. 12 together with creep curves under constant loading at $5,10,15$ an $20 \%$ of the short-term strength of the product. The tests have been conducted on the same product in parallel timing in the laboratory.

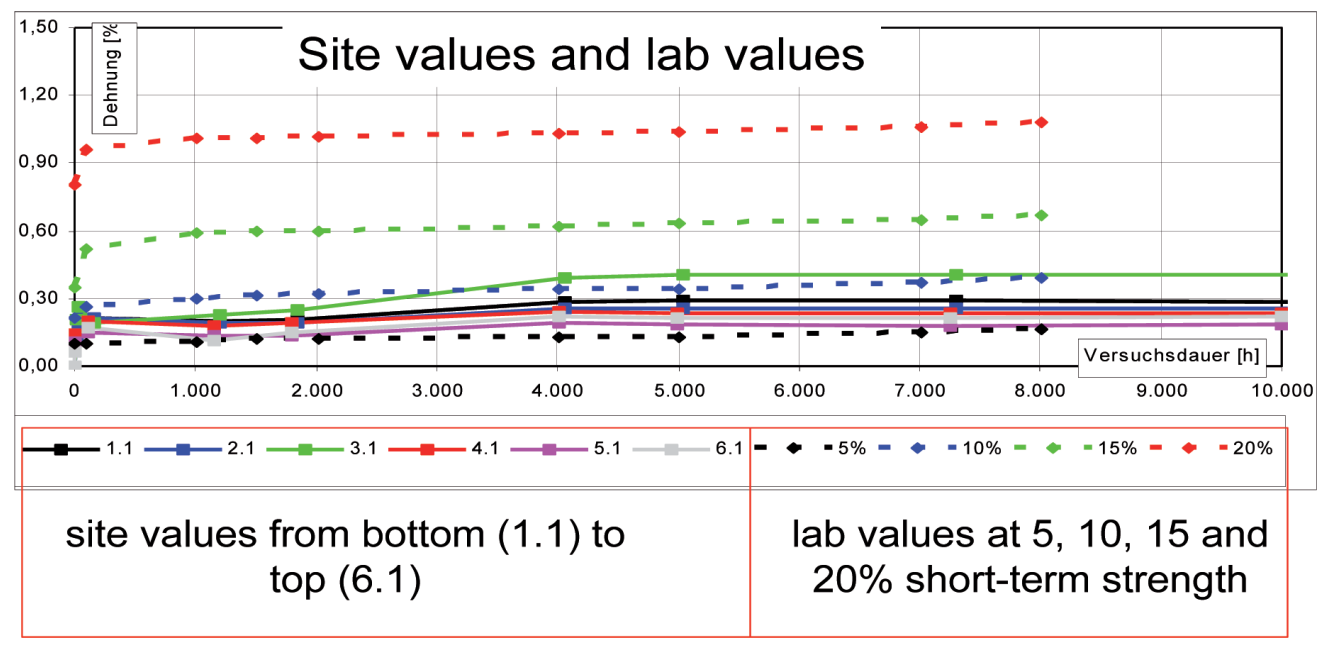

Fig. 16. Strain values of the geogrid from site strain gauges and lab creep tests.

The field measurements are showing strain values of the geogrids which have developed to about $0.3 \%$ corresponding to the creep strain (or elastic deformation?) 
range of only 5 to $10 \%$ of the short-term strength of the geogrid in the lab creep testing. Again it has to be considered that the geogrid at the landfill slope has been additionally exposed to construction damage and environmental deterioration which is not the case for the lab tested samples. Also this example is showing a geogrid application with a very high safety standard under full service conditions.

\subsection{IMPROVING THE DESIGN OF GEOGRID BASE REINFORCEMENT OF TRAFFIC AREAS}

Current design procedures for subgrade stabilization are typically expressed in terms of design charts of the different geogrid producers that provide the thickness of compacted aggregate required for unpaved roads as a function of subgrade strength for a road with and without a geosynthetic. Most design charts are based on bearing capacity considerations and do not directly account for the influence of traffic passes and deformation response (i.e. rutting). During EBGEO 2010 discussions no general design tools could be agreed upon for bearing capacity related target values to be achieved on top of the base course, but the use of design charts of experienced geogrid producers considering special product experience is recommended (EBGEO 2010).

An empirical design approach based on many years of application experience has been presented as a design disc (Heerten, 2007) for welded Secugrid ${ }^{\circledR}$ geogrids (Fig. 17).

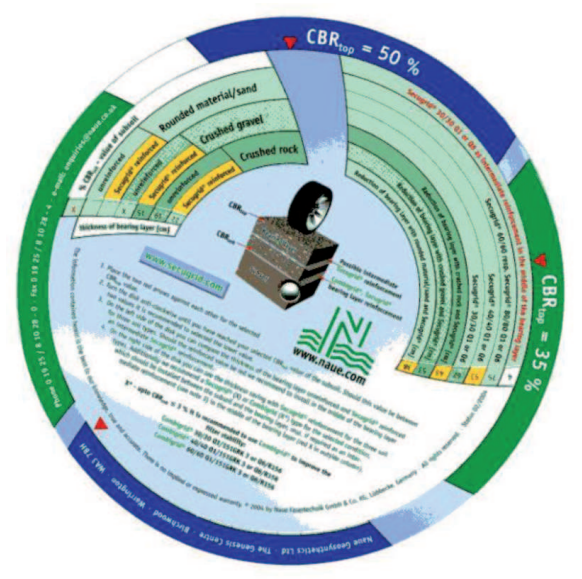

Fig. 17. Design disc for bearing layer reinforcement in traffic areas using welded Secugrid ${ }^{\circledR}$ geogrids.

Perkins et al. (2004) are working on a mechanistic-empirical design solution for base-reinforced flexible pavements, taking the traffic passes and deformation into consideration. This design solution uses components for the conventional pavement materials from a project, which serves as the basis for the new AASHTO mechanistic-empirical design guide. The design solution developed for reinforced pavements uses a finite 
element model to calculate pavement response and empirical damage models to relate strain-response to long term rutting. This design solution has recently been used successfully for unpaved haul roads.

Calibration of the model is performed by comparison of the model to large-scale laboratory unpaved roadway test sections constructed at GeoTesting Express (GTX, Atlanta, USA). These test sections used a subgrade and aggregate from an earlier project conducted in Lewistown, Montana. In particular, the calibration process allows for the permanent deformation properties of the aggregate and subgrade to be adjusted to match "field" rutting performance and provides an estimate of the effect of the reinforcement on reduction of excess pore water pressure generation in the subgrade during traffic loading.

The Montana project involved the construction of outdoor full-scale test sections. The test sections constructed are used for comparison to the laboratory test sections and show the applicability of the design charts for full-scale unpaved roads.

To develop design charts for unpaved roads using geosynthetics, the components necessary to complete are as follows:

I. Material Tests

II. Calibration Modeling

III. Design Chart Modeling

The material tests provide input parameters for the mechanistic-empirical model. Two geosynthetics, Secugrid ${ }^{\circledR}$ 20/20 Q1 and Secugrid ${ }^{\circledR}$ 30/30 Q1, are included in the test program. As one outcome it can be stated that measurement of pore water pressure generation during the test (Fig. 18) becomes decisive for interpretation and explaining the rut data and performance of the test sections.

The design disc (Fig. 17) gives required aggregate thickness versus subgrade CBR for different target composite CBR values measured on top of the base. Design values are presented for unreinforced roads and different types of aggregate (i.e. rounded material, crushed gravel, crushed rock). The rut depth or the number of traffic passes for which the charts apply is not specified. For a subgrade CBR of 2, the charts give a reduction of aggregate thickness ranging from approximately 28 to $36 \%$. Fig. 19 gives a reduction of $27 \%$ at a CBR of 2 with this reduction increasing for lower values of subgrade CBR (Perkins and Christopher, 2009).

Nevertheless, the design in Fig. 19 requires for less aggregate layer thickness compared to the design disc due to the fact, that for unbound pavements project-specific rutting can be accepted and has been considered by Perkins and Christopher, 2009. 


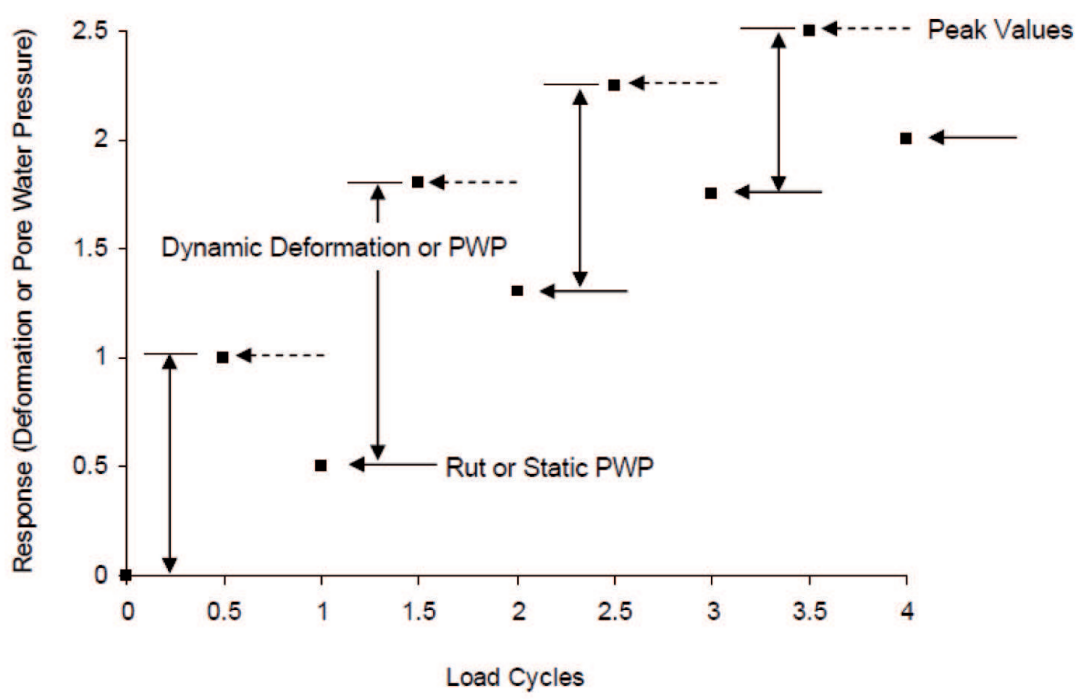

Fig. 18. Illustration of dynamic and static response measurements of pore water pressure in the soft soil underneath the geosynthetic.

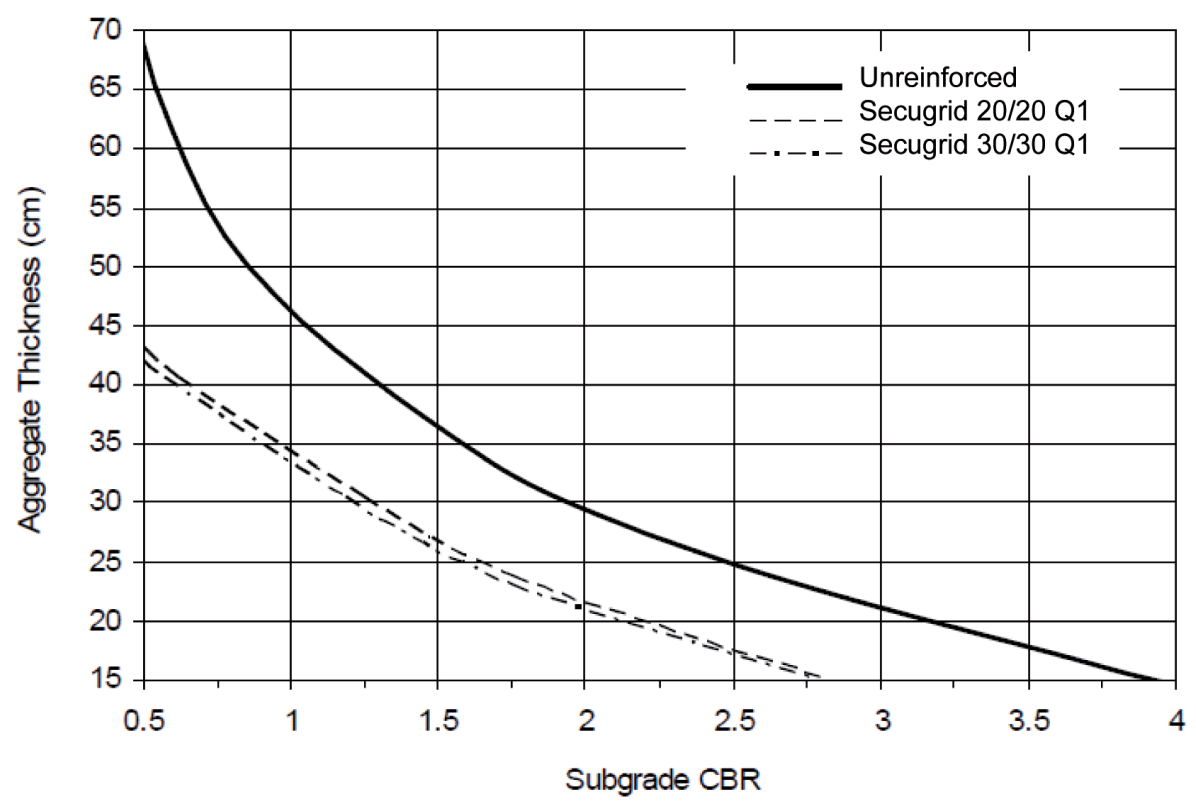

Fig. 19. Reinforced unpaved design curve - design scale. 
Finally, the intensive Perkins/Christopher investigations are giving confidence to the use of the presented design disc (Fig. 17) with the geogrid reinforced base course thickness being on the safe side.

\section{Conclusion}

The technical, economical and environmental advantages of geogrid reinforced soil structures will further pass the way that geogrid reinforced soil will become as common as steel reinforced concrete in the future. A NO-creep-reduction-approach for seismic loading has the first time been considered in Japanese railway structures design code, considering that creep is a material respond of visco-elastic synthetic reinforcing product and not a material deterioration or damage like metal corrosion. The ductile failure mode of geogrid reinforced soil structures can be seen as an advantage, too. In the light of very safe actual state-of-the-art design methods (EBGEO 2010, Germany) for geogrid reinforced soil strucutres, actual research is presenting a better understanding of the geogrid/soil interaction with soil confining and arching at and in between the geogrid layers, showing a big earth pressure reduction in the front zone of the reinforced structure with a moveable front element (Ruiken and Ziegler, 2010b). Lab and field data are presented, showing again very little geogrid deformation (often $\varepsilon<<1 \%$ ), questioning the actual reinforcing material test in creep tests with strain values far above the limiting strain values of the soil in the geogrid/soil compound material. The initial stiffness (secant modulus) and possibly the ELASTIC behaviour of the geogrid at strain values $\varepsilon$ less than 1 or $2 \%$ will be the more decisive design parameter in the future. But there is still a lot of research needed before we fully understand the geogrid/soil interaction and are able to carry out corresponding numerical calculations and designs. In the meantime we can continue constructing robust and economic geogrid reinforced soil structures with the state-of-the-art design like the new EBGEO 2010 recommendations or further developed design charts for base course geogrid reinforcing of traffic areas (Perkins et al., 2009).

\section{REFERENCES}

1. EBGEO, Empfehlungen für den Entwurf und die Berechnung von Erdkörpern mit Bewehrungseinlagen aus Geokunststoffen (EBGEO). 2. vollständig überarbeitete und erweiterte Auflage. Herausgeber: Deutsche Gesellschaft für Geotechnik e.V., ISBN 978-3-433-02950-3, Verlag Ernst \& Sohn, Berlin, April 2010.

2. T. EgloffsteIn, Ökologischer Vergleich zwischen Bauweisen mit mineralischen Baustoffen und Bindemitteln sowie Bauweisen mit Geokunststoffen. Zeitschrift geotechnik 32 (2009) Nr. 3.

3. FGSV-Merkblatt 551, Merkblatt für Bodenverfestigungen und Bodenverbesserungen mit Bindemitteln. Veröffentlichung der Forschungsgesellschaft für Straßen- und Verkehrswesen, 2004.

4. G. HeERTEN, Improving the Bearing Capacity of Soils with Geosynthetics. ${ }^{\text {th }}$ International Geotechnical Conference, Bratislava, Slovakia, June 2007. 
5. G. Heerten, J. Klompmaker, L. Vollmert, The geomechanical behaviour of geogrids. $9^{\text {th }}$ International Geotechnical Conference, Bratislava, Czech Republic, June 2009.

6. G. HeERTen, Reduction of climate-damaging gases in geotechnial engineering by use of geosynthetics. International Symposium on Geotechnical Engineering, Ground Improvement, and Geosynthetics for Sustainable Mitigation and Adaptation to Climate Change including Global Warming, Bangkok, Thailand, December 2009. (Keynote lecture).

7. G. Heerten, Improved design methods for geogrid soil reinforcement and green-geo-engineering aspects, $14^{\text {th }}$ Danube-European Conference on Geotechnical Engineering, Bratislava, Slovakia, June 2010.

8. J. Koerner, T-Y. Soong, R.M. Koerner, Retaining Wall Costs in the USA. GRI Report No. 20, Geosynthetic Institute, Folsom, Penna., June 18, 1998, 38 pages.

9. S.W. Perkins, B.R. Christopher, E.L. Cuelho, G.R. Eiksund, I. Hoff, C.W. Schwartz, G. Svan $\emptyset$, A. Watn, Development of Design Methods for Geosynthetic Reinforced Flexible Pavements. U.S. Department of Transportation, Federal Highway Administration, Washington, DC, FHWA Report Reference Number DTFH61-01-X-00068, 263p., 2004.

10. S.W. Perkins, B.R. Christopher, Development of design charts for unpaved roads using NAUE Geosynthetics. Western Transportation Institute College of Engineering Montana State University, 2009.

11. A. Ruiken, M. Ziegler, Untersuchungen am Verbundstoff Geogitterbewehrter Boden. 9. Sächsisches Bautextilien-Symposium, BAUTEX 2010, Chemnitz, Januar 2010.

12. A. Ruiken, M. Ziegler, Determination of the Soil Confining Effect of Geogrids. $14^{\text {th }}$ Danube-European Conference on Geotechnical Engineering, Bratislava, Slovakia, June 2010.

13. SETAC, Guideline for Life Cycle Assessment - A "Code of Practice". Society for Environmental Toxicology and Chemistry, SETAC Workshop held at Sesimbra, Portugal, 31 March - 3 April 1993, Edition 1, Brussels and Pensacola (Florida).

14. F. Tatsuoka, Recent developments in practice and research of geosynthetic-reinforced earth structures in Japan. Keynote lecture, 30. Baugrundtagung, Dortmund, September 2008.

15. F. Tatsuoka, President's Corner, IGS News, Vol. 25, No. 3, November 2009.

16. L. Vollmert, J. Klompmaker, M. Holý, Steep Slopes Following European Design Codes - Prediction and Field Monitoring of Geogrid-Strains and Earth Pressure on the Facing-System. 14 ${ }^{\text {th }}$ Danube-European Conference on Geotechnical Engineering, Bratislava, Slovakia, June 2010.

17. K. Werth, Steil, lang und kurvig - Herausforderungen bei Bemessung und Ausführung von Oberfächenabdichtungen in Böschungen unter Einsatz von Geogittern. Fachtagung "Die sichere Deponie - Sicherung von Deponien und Altlasten mit Kunststoffen", SKZ Würzburg, Februar 2010.

18. M. Ziegler, G. Heerten, A. Ruiken, Progress in the understanding of geosynthetic/soil composite material behaviour in geosynthetic reinforced earth structures. GeoAmericas 2008, The First Pan American Geosynthetics Conference and Exhibition, Cancun, Mexico, March 2008.

Remarks on the paper should be sent to the Editorial Office

no later than September 30, 2011
Received December 15, 2010

revised version

March 18, 2011 